\title{
Uranometría Argentina and the constellation boundaries
}

\author{
Santiago Paolantonio ${ }^{1}$ and Beatriz García ${ }^{2}$ \\ ${ }^{1}$ Observatorio Astronómico Córdoba, Argentina. email: paolantoniosantiago@gmail.com \\ ${ }^{2}$ ITeDAM-CONICET-CNEA-UNSAM, UTN Mendoza, Lab. Pierre Auger
}

\begin{abstract}
The astronomical community accepts the division of the celestial sphere into 88 constellations, according to what was established by the IAU. In the first Assembly of 1922 the use of Latin names for constellations and their abbreviations was resolved. The pending issue of the limits of the constellations was discussed in the next meeting and Eugène Delporte had the responsibility for the complete theoretical demarcation. For his work, Delporte took into account what was done half a century earlier in the famous work Uranometría Argentina, published in 1877 and 1879, under the supervition of Benjamin Gould. In ths presentation we discusse the situation at the moment when the constellation boundaries were proposed using arcs of RA circles and parallels of declination, choosing them in such a way that they did not deviate too much from those used in the most important celestial atlas of the time, and minimizing the changes of which constellations stars would belong to.
\end{abstract}

Keywords. History of astronomy, Uranometría Argentina, constellation boundaries

\section{Introduction}

The current astronomical community unanimously accepts the division of the celestial sphere into 88 constellations, according to what was established by the International Astronomical Union. After the formation of the Union, in the first Assembly of 1922 the exclusive use of the Latin names for the constellations and their abbreviations was resolved with the three letter system in force today. In the following meeting, the Belgian National Committee of Astronomy examined the pending issue of the limits of the constellations, presenting a motion to review them. The astronomer Eugène J. Delporte was given the responsibility of the complete theoretical demarcation, and he periodically informed the rest of the members of the subcommission, to take into account his recommendations, a form of work that avoided possible conflicts due to questions of nationalism. For his task Delporte largely used the methodology proposed in the Uranometría Argentina.

\section{The work}

\subsection{The cover}

In his work, "Report of Commission 3 of the IAU, Delimitation scientifique des constellations", (Fig. 1, left) presented in 1930 (Delporte 1930), Delporte took especially into account what was done half a century earlier in the famous work of the Uranometría Argentina, published in the Resultados de Observatorio Nacional Argentino (Fig. 1, right) (Gould 1879; Paolantonio \& Minniti 2001). The reason for this action was due to the quality of the work done in Córdoba and the detailed study carried out by its director, Benjamin A. Gould. 


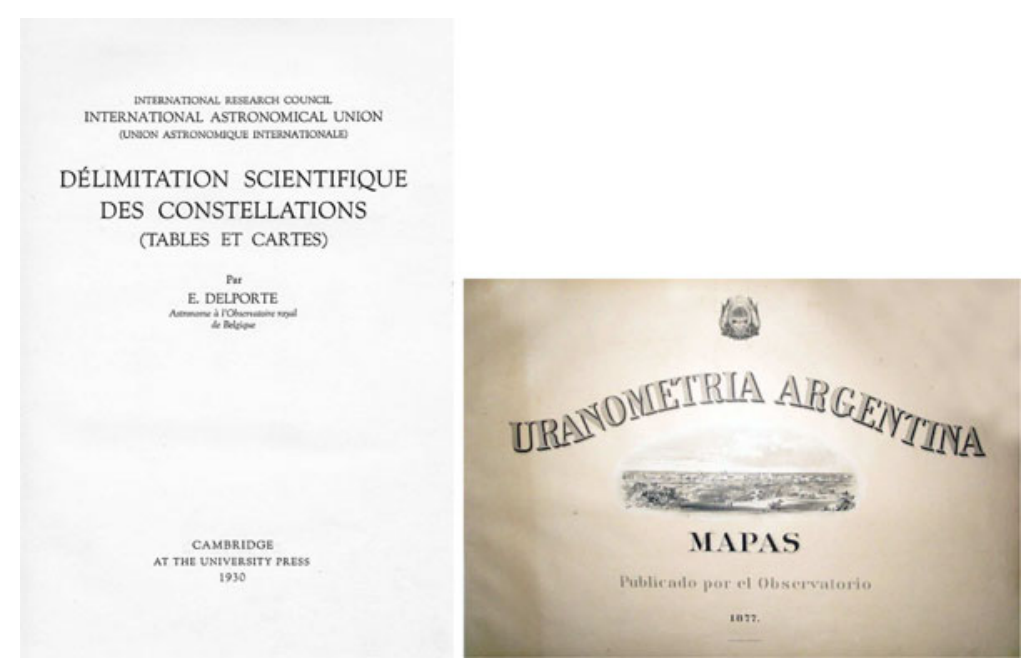

Figure 1. Cover of the Report of E. J. Delporte presented in 1930 (left). The atlas of the Uranometría Argentina was published in 1877, while the catalogue was published in 1879 (right). Córdoba Astronomical Observatory Library.

\subsection{Original observing notebooks}

The reason for using the Uranometría Argentina was based on the fact that in this work a detailed investigation was made of the current situation at that time, unifying the stellar denominations and solving a proposal of the limits of the constellations, which used arcs of right ascension circles and parallels of declination, choosing them in such a way that they did not deviate too much from those used in the most important atlasses of the time, and minimizing the changes of which constellations stars would belong to. A magnitude scale was set up to the 7 th magnitude.

The first observation for the new southern uranometry was made on November 14,1870 by the assistant, Williams Morris Davis. The measurements of position and brightness, made by the assistants from their lodgings in the centre of Córdoba city, were written down in notebooks, which are now kept at the Museum of the Astronomical Observatory of Córdoba (Fig. 2)

\section{The maps}

Delporte opted to use the reference equinox of 1875.0, to coincide with the Uranometría Argentina (Fig. 3) in order to form a set with it, although by that time the positions of stars were already given referred to 1900.0. One of the most important reasons for the need to clearly define constellation boundaries was the issue of variable star names. Again in this respect the Uranometría Argentina had great importance, since in the same work 208 variable stars or suspected variable stars were included, at a time when the known list of variables did not surpass one hundred and fifty. Also, it is in this work that the stellar structure known today as Gould's Belt was described.

In order to obtain a total homogeneity between the two hemispheres, the boundaries of the southern constellations proposed with oblique arcs were changed (Fig. 4). The work was successful, and only some boundariess took apparently capricious paths, being products of the orders of Commission 22 "Meteors" and mainly of the Commission 27 "Variable stars", which requested not to modify the names of the known variable stars until that moment. This last condition produced at the same time a few reforms of the limits of the southern asterisms, to preserve the names of the variables TV and UW 


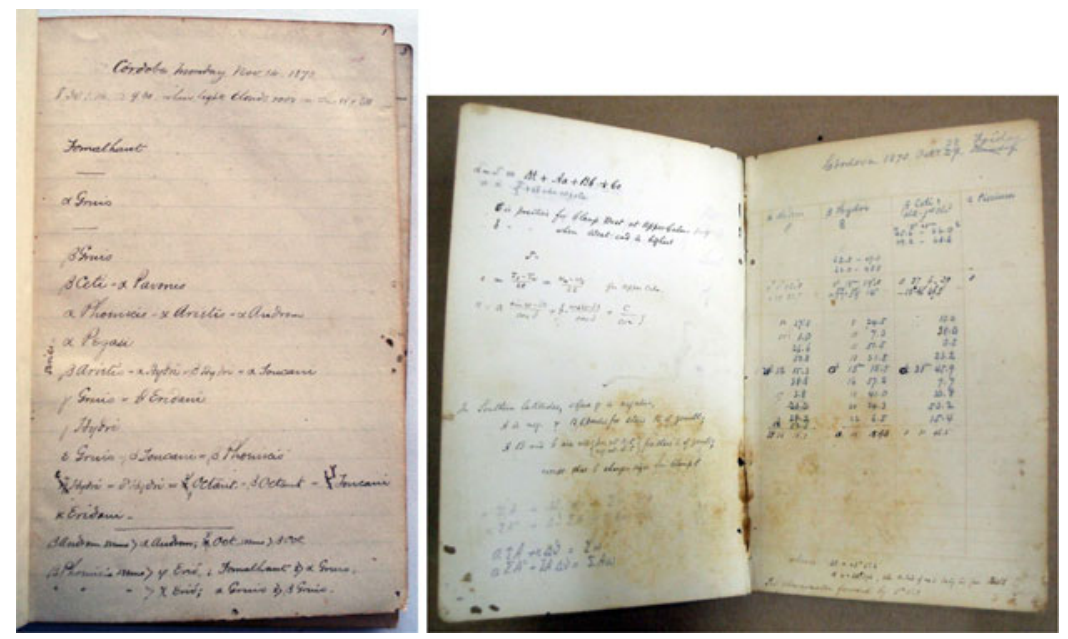

Figure 2. Original notebooks for the Uranometría Argentina. Córdoba Observatory Museum.
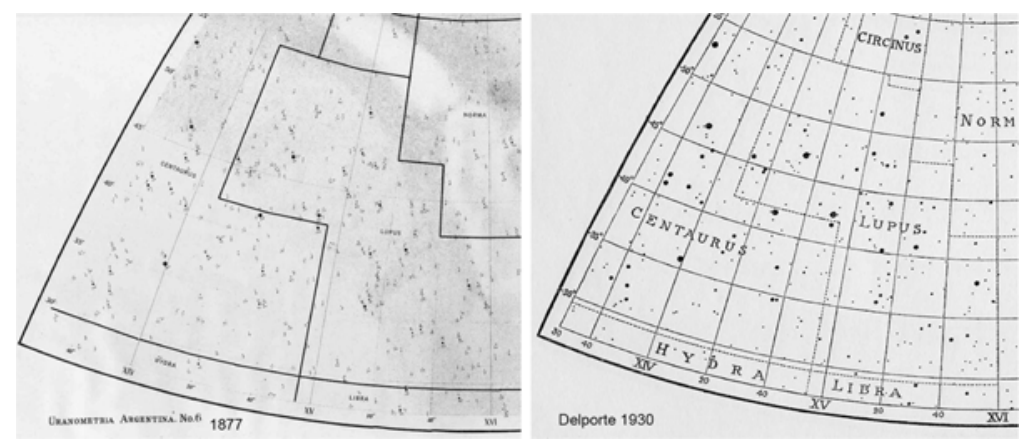

Figure 3. Details of Delporte's maps. The coincidences between the limits of the constellations of the Uranometría Argentina (left), (the limits for a better visualization are highlighted) and those proposed by Delporte in 1930 (right), are evident. Córdoba Astronomical Observatory Library.

Ophiuchi, DG Aquilae, RR Normae, T Circini and U Tucanae. In all cases, care was taken that none of the stars included in the Uranometría Argentina catalogue changed constellations.

For the maps, the projection chosen in the Uranometría Argentina was also used (Fig.5). Although they were drawn on the same scale, for reasons of economy they were published in a smaller size, of only 40 per cent of the original.

\section{Conclusion}

In summary, the limits of the current constellations were defined taking as reference the proposal made in the Uranometría Argentina. This choice was not arbitrary, but a consequence of the quality of the work done in the Argentine National Observatory and the detailed study carried out by its director, Benjamin A. Gould.

While the body of astronomers of the observatory made the estimations and measurements, revisions and the necessary calculations, Gould investigated in detail the distribution of the stars in the sky, fixed a scale of magnitudes up to the 7th and in particular devoted enormous efforts to standardize the stellar denominations and the 

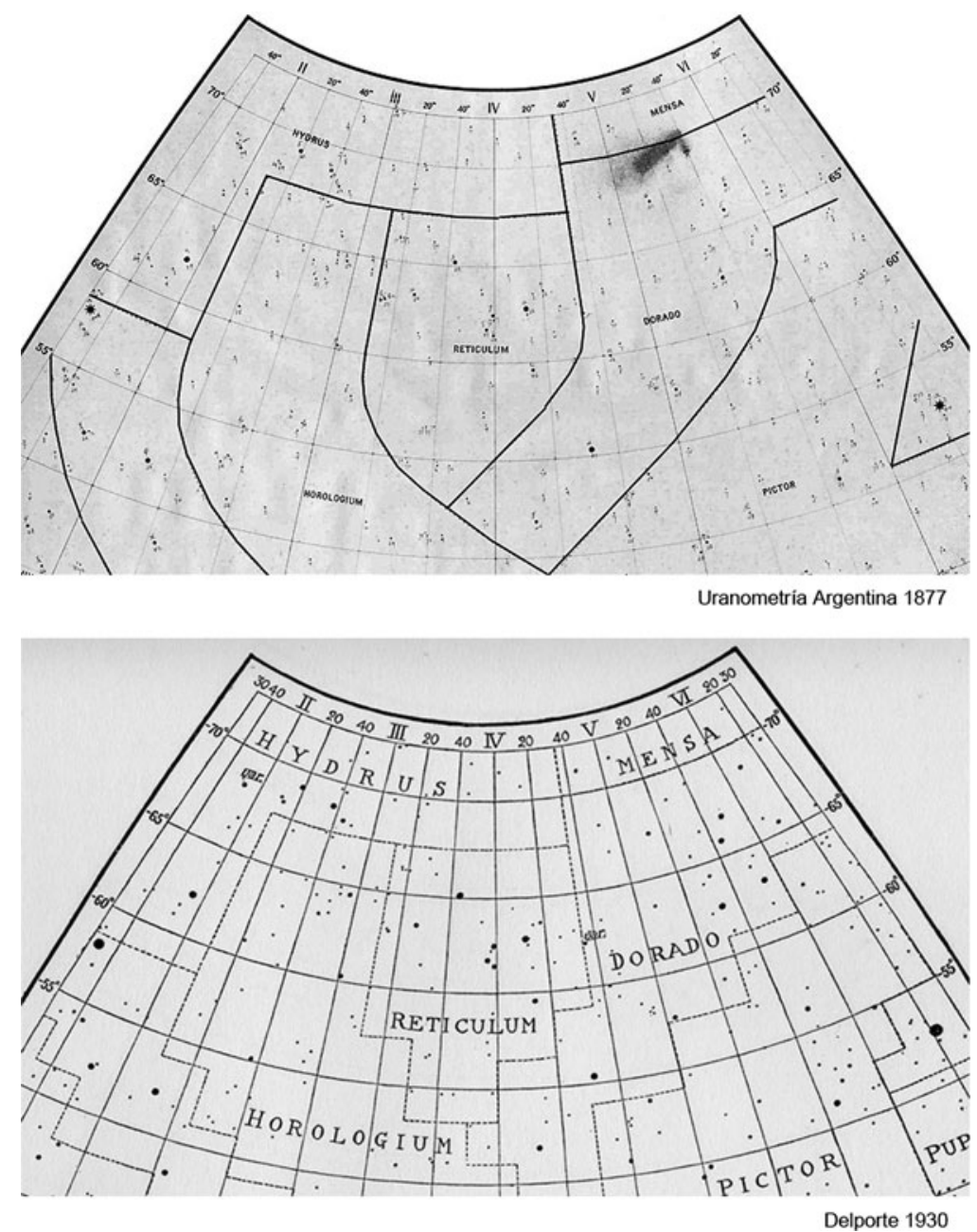

Figure 4. Details of the maps where the modifications introduced in the limits of the constellations of the Uranometría Argentina (top) and those resolved by Delporte (bottom) can be appreciated. Córdoba Astronomical Observatory Library.

constellation boundaries, with the express intention of overcoming the many ambiguities existing at that time.

The director stresses the importance of the boundaries of asterisms being rigidly and unequivocally defined, particularly in relation to variable stars, objects that began to be the focus of ever greater attention of the astronomical community at that moment.

As a touch of colour, it is good to choose to close this contribution with a citation by Gould: "After long consideration and consultation with other astronomers... the total abandonment of the venerable constellation Argo has caused me much regret" ((Gould 1879), p 62) (Fig. 6). This is evidence of one of the characteristics of astronomy, namely, that it is a science but also an art.

\section{Acknowledgements}

The authors want to thank the Córdoba Observatoy Museum, the IAU, the Argentinean National Council of Scientific Research and the National Tech. University for supporting this work. We are grateful to Silvina Perez for the design of the poster. 

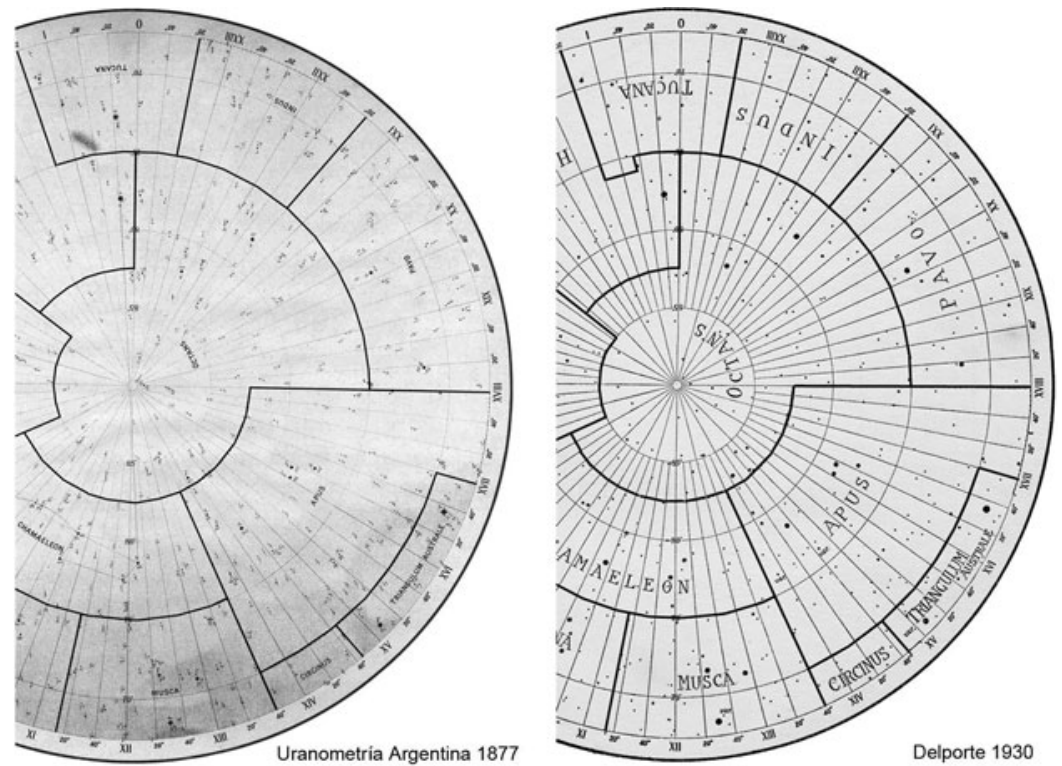

Figure 5. Comparison between the maps of the Southern Pole zone of the Uranometrí Argentina (left) and that of Delporte. The limits are the same, except for a small section in Tucana. Córdoba Astronomical Observatory Library.
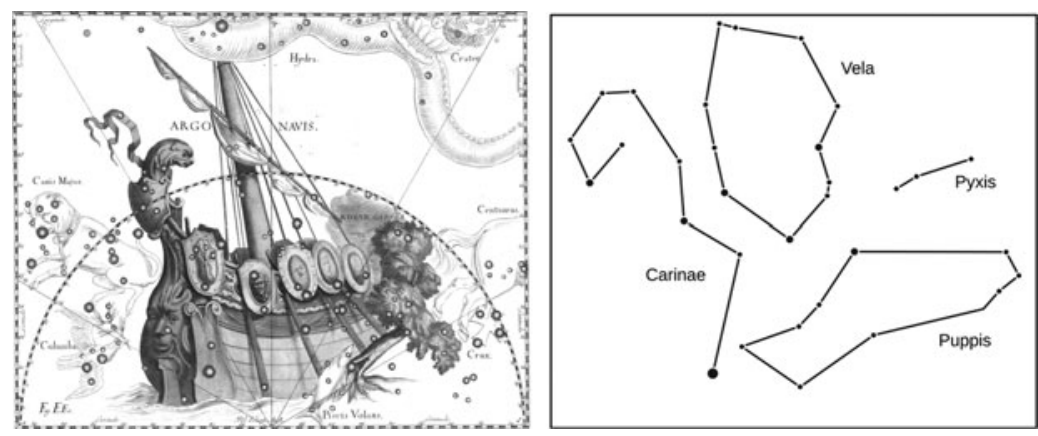

Figure 6. Hevelius Argo Navis (left). Actual constellations of Carina, Puppis and Vela (right).

\section{References}

Delporte, E. (1930), Délimitation scientifique des constellations (tables et cartes). Cambridge University press

Gould, B. A. (1879), Uranometría Argentina, Catálogo y Atlas (1877). Posiciones y brillos de 7756 estrellas más brillantes que magnitud 7.0, ubicadas dentro de los $100^{\circ}$ del polo sur (1875.0). Resultados del Observatorio Nacional Argentino, Vol. I. Buenos Aires, Imprenta de Pablo Emile Coni

Paolantonio, S. \& Minniti, D. (2001), Uranometría Argentina 2001. In Historia del Observatorio Nacional Argentino. SECyT, OAC, Universidad Nacional de Córdoba 